\title{
Influence of roughness parameters on coefficient of friction under lubricated conditions
}

\author{
PRADEEP L MENEZES $^{1 *}$ KISHORE $^{1}$ and SATISH V KAILAS ${ }^{2}$ \\ ${ }^{1}$ Department of Materials Engineering, Indian Institute of Science, \\ Bangalore 560012 \\ ${ }^{2}$ Department of Mechanical Engineering, Indian Institute of Science, \\ Bangalore 560012 \\ e-mail: lancy@mecheng.iisc.ernet.in
}

\begin{abstract}
Surface texture and thus roughness parameters influence coefficient of friction during sliding. In the present investigation, four kinds of surface textures with varying roughness were attained on the steel plate surfaces. The surface textures of the steel plates were characterized in terms of roughness parameter using optical profilometer. Then the pins made of various materials, such as $\mathrm{Al}-4 \mathrm{Mg}$ alloy, $\mathrm{Al}-8 \mathrm{Mg}$ alloy, $\mathrm{Cu}, \mathrm{Pb}, \mathrm{Al}, \mathrm{Mg}, \mathrm{Zn}$ and $\mathrm{Sn}$ were slid against the prepared steel plates using an inclined pin-on-plate sliding tester under lubricated conditions. It was observed that the surface roughness parameter, namely, $R_{a}$, for different textured surfaces was comparable to one another although they were prepared by different machining techniques. It was also observed that for a given kind of surface texture the coefficient of friction did not vary with $R_{a}$. However, the coefficient of friction changes considerably with surface textures for similar $R_{a}$ values for all the materials investigated. Thus, attempts were made to study other surface roughness parameters of the steel plates and correlate them with coefficient of friction. It was observed that among the surface roughness parameters, the mean slope of the profile, $\operatorname{Del} a\left(\Delta_{a}\right)$, was found to explain the variations best.
\end{abstract}

Keywords. Roughness parameters; surface texture; friction; lubrication.

\section{Introduction}

Surface texture is considered to be the local deviations of a surface from its ideal shape. It is one of the most important factors that influence coefficient of friction during sliding. Attempts have been made earlier to study the effect of surface textures on coefficient of friction during sliding (Menezes et al 2006a-e; Lakshmipathy \& Sagar 1992; Määttä et al 2001; Hu \& Dean 2000; Staph et al 1973; Koura 1980; Malayappan \& Narayanasamy 2004; Gadelmawla et al 2002; Lundberg 1995). Staph et al 1973 studied the effect of surface texture and surface roughness on scuffing using 'caterpillar disc tester'. The authors used steel discs of varying roughness

*For correspondence 
and texture (honed, circumferentially ground with low and high roughness, and cross-ground) and concluded that both surface texture and surface roughness affect frictional behaviour. Koura (1980) studied the effect of surface texture on friction mechanism using an universal testing machine. Steel specimens were prepared to various degrees of roughness by grinding, lapping and polishing. The results showed that the behaviour of surfaces and thus friction during sliding depends on the degree of roughness. Malayappan and Narayanasamy (2004) studied the bulging effect of aluminium solid cylinders by varying the frictional conditions at the flat die surfaces. Different machining processes like grinding, milling, electro-spark machining, and lathe turning with emery finish were produced on the flat dies to vary the frictional conditions. It was concluded that the barreling depends on friction and thus on surface finish.

The roughness parameter, which describes the surface texture, also plays an important role in determining friction. Several well-known roughness parameters (Gadelmawla et al 2002) were used to quantify surface texture. The surface roughness parameter like $R_{a}$ is used in general, to describe a surface. However, it is possible that two surface textures can have the same $R_{a}$, but their frictional characteristics could be different (Menezes et al 2006a,b). Considerable amount of work also has been done to study the influence of various roughness parameters on coefficient of friction (Lundberg 1995; Myers 1962; Hirst \& Hollander 1974; Bello \& Walton 1987; Wieleba 2002; Singh et al 2005). Lundberg (1995) studied the influence of surface roughness on normal sliding lubrication and reported that the $R_{\max }$ and $R_{t}$ were the most significant surface roughness parameters with regard to influence on lubrication. Myers (1962) conducted experiments using an inclined plane sliding tester to study the coefficient of friction between a test slider and sample disks. Twelve samples surfaces were fabricated from cold-rolled steel disks. Five of these had lapped finishes while the others had ground finishes. Myers (1962) studied the correlation coefficient between coefficient of friction with the three r.m.s. values corresponding to (i) surface profiles, (ii) first derivative of surface profiles and (iii) second derivative of surface profiles and concluded that the second one, namely, the r.m.s. of first derivative was useful in predicting friction. Hirst \& Hollander (1974) indicated that the scuffing behaviour of isotropic stainless steel surfaces under low speed and boundary lubricated sliding conditions was controlled by two measures of topography; the r.m.s. roughness and the correlation distance, $\beta^{*}$. These parameters were regarded as asperity measurements proportional to the average height and average wavelength respectively. Bello \& Walton (1987) studied the interaction of surface roughness and lubrication at the tool-metal interface in sliding contact. In their experiment, strips of commercial pure aluminum were pulled through steel dies designed to give partial simulation of the conditions which exist in the flange and die radius profile regions of the deep drawing process. Bello $\&$ Walton (1987) found that the conventional surface roughness parameters $\left(R_{a}\right.$, skewness, kurtosis and peak density) do not provide a satisfactory functional characterization of the surface in context of the friction developed in sliding contact. Bello \& Walton (1987) defined a new surface roughness parameter called bearing length product (a product of average peak width and $R_{a}$ ), and showed it to have a functional relationship with the coefficient of friction. Wieleba (2002) studied the statistical correlation between the coefficient of friction and wear rate of PTFE composites with steel counterface under dry sliding conditions. Wieleba (2002) reported that the roughness parameters related to the shape of asperities of the profile (i.e. mean peak spacing $\left(S_{m}\right)$, average profile slope $\left(\Delta_{\alpha}\right)$ and core roughness depth $\left(R_{k}\right)$ ) had the strongest influence on the coefficient of friction, while the parameters related to the height of asperities of the profile (i.e. the mean peak height $\left(R_{p}\right)$, reduced peak height $\left(R_{p k}\right)$, comprehensive ratio of roughness $(\Delta)$ and maximum roughness depth $\left(R_{y}\right)$ had the strongest 
influence on the wear of PTFE composites. Additionally, Wieleba (2002) concluded that the mean third highest peak-to-valley height, $R_{3 z}$, parameter appeared to be the most universal one. Singh et al (2005) investigated the role of three-dimensional (3-D) surface topographic features of four precision finished surfaces (viz. ground, hard turned, honed, and isotropic) on their frictional response. Based on a detailed 3-D surface characterization, Singh et al (2005) concluded that the amplitude parameter, $S_{q}$ (r.m.s. deviation of surface), spatial parameters, $S_{d s}$ (density of summits) and $S_{t d}$ (texture direction) play an important role in determining the frictional behaviour of the surfaces.

It was observed from literature that many individual or hybrid surface roughness parameters are in vogue. These include amplitude, spatial and hybrid parameters. However, it was noticed that like friction, the correlation coefficient between coefficient of friction and roughness parameters, was system dependent. It is important to consider both spatial and amplitude parameters to define the surfaces and relate these parameters with coefficient of friction. Thus, keeping this view in mind, this paper presents the results of an experimental study aimed at understanding the frictional response of various materials sliding against various surface textures. In addition, attempts have been made to identify the surface roughness parameters that strongly correlate with coefficient of friction during sliding.

\section{Experimental}

Four types of surface textures were produced on 080 M40 (EN8) steel plates. Type I surfaces were produced on the steel plates with varying roughness by dry grinding the steel plates against dry emery papers of $220,400,600,800$ or 1000 grit size. For this type of surface texture, care was taken so that the grinding marks were unidirectional in nature. Type II surfaces were generated on steel plates with varying roughness by moving the steel plate on dry emery papers of $220,400,600,800$ or 1000 grit size along a path with the shape of an 8 for about 500 times. Type III surfaces were similar to the Type I produced, but the grinding marks direction was perpendicular to that of Type I. Type IV surfaces with varying roughness were generated under wet grinding conditions using a polishing wheel with any one of the three abrasive media such as $\mathrm{SiC}$ powder (600 and 1000 grit), $\mathrm{Al}_{2} \mathrm{O}_{3}$ powder $(0.017 \mu \mathrm{m})$, and diamond paste $(1-3 \mu \mathrm{m})$. Figures 1a-c show the profiles of steel plate surfaces along with its $3 \mathrm{D}$ roughness parameter, $R_{a}$, generated by Types I, II, and IV respectively. Note that the $R_{a}$ of the three surfaces is similar despite different preparation techniques employed.

Experiments were conducted using an inclined pin-on-plate sliding tester, details of which were explained in earlier paper (Menezes et al 2006c). In the present study, soft material made of pure $\mathrm{Cu}(99.99$ wt.\%) was used as pins while steel plates made of $080 \mathrm{M} 40$ formed the counterpart hard material. The pins were $10 \mathrm{~mm}$ long, $3 \mathrm{~mm}$ in diameter with a tip radius of $1.5 \mathrm{~mm}$. The dimensions of the $080 \mathrm{M} 40$ steel plates were $28 \times 20 \times 10 \mathrm{~mm}$ (thickness). The pins were first machined, and then electro-polished to remove any work-hardened layer that might have formed during the machining. Before each experiment, the pins and steel plates were thoroughly cleaned first in an aqueous soap solution and then with acetone in an ultrasonic cleaner. The steel plate was fixed horizontally in the vice of the pin-on-plate sliding tester and then the vice-set-up was tilted so that surface of the plate makes an angle of $1^{\circ} \pm 0 \cdot 05^{\circ}$ with respect to horizontal base. Then pins were slid at a sliding speed of $2 \mathrm{~mm} / \mathrm{s}$ against the prepared steel plates starting from lower end to the higher end of the inclined surface for a track length of $10 \mathrm{~mm}$. Normal load was varied from 1 to $120 \mathrm{~N}$ during the test. The advantage of $1^{\circ}$ inclination of the steel plate was that from a single experiment, the 


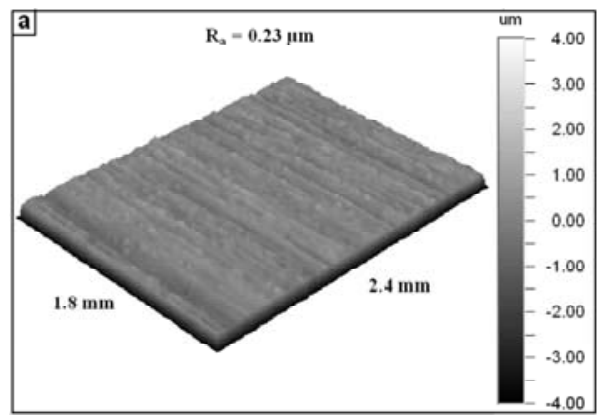

(a)

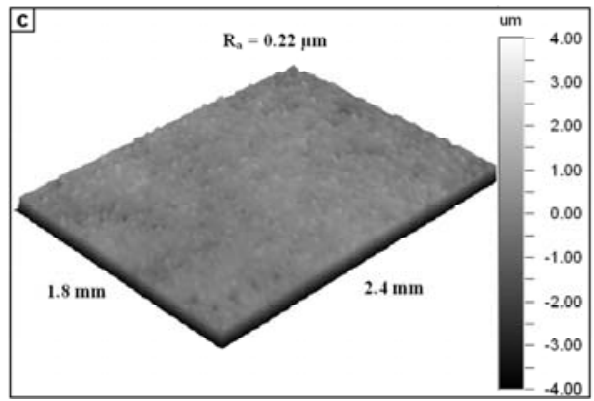

(c)

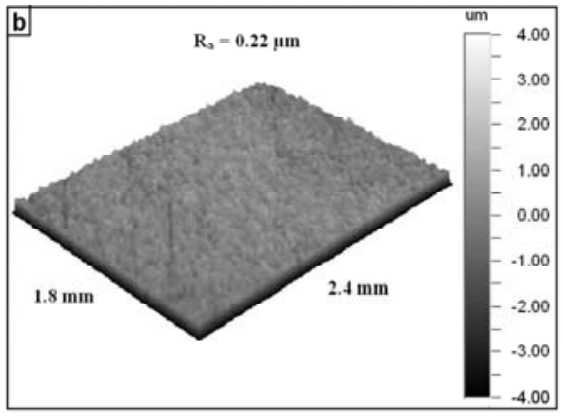

(b)

Figure 1. 3D profiles of (a) Type I, (b) Type II and (c) Type IV surface textures.

effect of normal load (up to the test limit of $120 \mathrm{~N}$ ) on the coefficient of friction could be studied (Menezes et al 2006b). Experiments were conducted under lubricated conditions on each plate in ambient environment. Before the tests, a drop (i.e. $0.05 \mathrm{ml}$ ) of commercially available engine oil lubricant ('Shell' make 2T oil) was applied on the surface of the steel plate. The viscosity of lubricant oil was found to be $40 \mathrm{cSt}$ at $40^{\circ} \mathrm{C}$ and had the extreme pressure additive Zinc Dialkyl Dithiophosphate (ZDDP). The presence of ZDDP was confirmed using Fourier Transform Infrared spectroscopy technique. For a given surface texture, the tests were conducted for five levels of surface roughness. The profiles and surface roughness parameters of the steel plates were measured in the direction of the sliding on the bare surface away from the wear tracks using an optical profilometer. It was reported that the coefficient of friction depends on direction of sliding (Menezes et al 2006a,b). For this reason, 2D roughness parameters, along the sliding direction of the pin, were considered in this study. The coefficient of friction values obtained in the experiments were correlated with roughness parameters of the steel plates. The work reports additionally the correlation coefficient between coefficient of friction and roughness parameters for various materials such as $\mathrm{Al}-4 \mathrm{Mg}$ alloy, $\mathrm{Al}-8 \mathrm{Mg}$ alloy, pure $\mathrm{Pb}$ (99.98 wt.\%), pure $\mathrm{Al}$ (99.997 wt.\%), pure $\mathrm{Mg}$ (99.98 wt.\%), pure $\mathrm{Zn}$ (99.9 wt.\%) and pure Sn (99.98 wt.\%) obtained under similar testing conditions.

\section{Results}

Figure 2 shows the variation of average coefficient of friction with $R_{a}$ when $\mathrm{Cu}$ pin slides on various surface textures under lubricated conditions. The average coefficient of friction values were calculated for a sliding distance of $10 \mathrm{~mm}$ and loads were varying from 1 to 


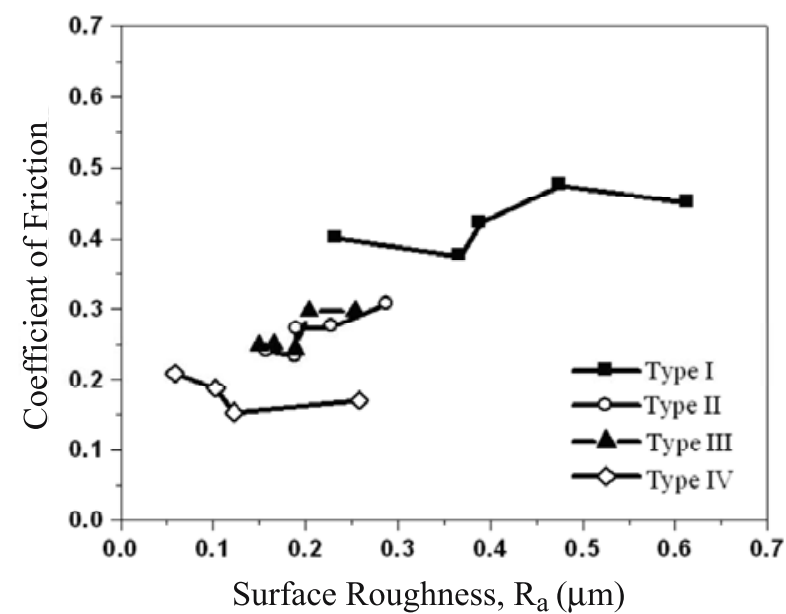

Figure 2. Variation of average coefficient of friction with surface roughness $\left(R_{a}\right)$ for various types of surface textures under lubricated conditions.

$120 \mathrm{~N}$ in the tests. It was observed that the coefficient of friction did not vary much under both sliding distance and normal loads. It can be seen from this figure that no particular relation exists between $R_{a}$ and coefficient of friction. In addition, it can be seen that for a given kind of texture, the coefficient of friction did not vary much with $R_{a}$. Here, the range of surface roughness $\left(R_{a}\right)$ varies between 0.05 and $0.65 \mu \mathrm{m}$ for different textured surfaces. It can also be noticed from figure 2 that, for a given $R_{a}$ value, the coefficient of friction changes considerably with surface texture. Thus, it is important to characterize the surface texture by means of surface roughness parameters. Many roughness parameters were investigated and these are documented in the literature (Gadelmawla et al 2002). It is possible that two surface textures can have the same $R_{a}$, but their frictional characteristics could be different. This fact can also be observed in figure 2 where for a given $R_{a}$, the coefficient of friction varies considerably. Hence, it is important to study other roughness parameters of surface texture and to correlate them with the coefficient of friction. The roughness parameter changes during surface preparation, owing to texture and hence affects the coefficient of friction. Thus, efforts were made to correlate surface roughness parameters with coefficient of friction. For doing this, twenty-five surface roughness parameters were taken under consideration. The description of these roughness parameters are presented in table 1.

Figure 3 shows the results of the correlation analysis between surface roughness parameters and coefficient of friction under lubricated conditions. The degree of complexity of surface shape could be represented by a value called fractal dimension (Feder 1988) — a higher degree of complexity shows a bigger value. Most of surface structure has complicated shapes that they cannot be explained by the euclidean geometry. These shapes occur repetitively even when they are observed under different magnifications. This is called self-similarity. Fractal refers to a structure having self-similarity. Thus, as a new geometry that can describe the structural irregularities and complexities of the natural system, fractal is widely used to explain the natural substance. Among the many ways of calculating fractal dimensions (Feder 1988) such as (a) the power spectrum, (b) the cover, (c) the variation and (d) the rectangular cell counting, it was calculated using the variance method as it was suggested that the variation method was substantially more accurate than the other methods. This method is described briefly by Hasegawa et al (1996). As anticipated, the correlation coefficient values varied over a wide range, from 0.04 to as high as 0.92 , in absolute values, depending on the sur- 
Table 1. Description of surface roughness parameters.

\begin{tabular}{ll}
\hline $\begin{array}{l}\text { Roughness } \\
\text { parameter }\end{array}$ & \\
\hline$R_{q}(\mu \mathrm{m})$ & Root mean square roughness \\
$R_{a}(\mu \mathrm{m})$ & Average roughness \\
$R_{t}(\mu \mathrm{m})$ & Maximum height of the profile \\
$R_{p}(\mu \mathrm{m})$ & Maximum profile peak height \\
$R_{v}(\mu \mathrm{m})$ & Maximum profile valley depth \\
$R_{s k}$ & Skewness \\
$R_{k u}$ & Kurtosis \\
$R_{z}(\mu \mathrm{m})$ & Average maximum height of the profile \\
$R_{m a x}(\mu \mathrm{m})$ & Maximum roughness depth \\
$R_{p m}(\mu \mathrm{m})$ & Average maximum profile peak height \\
$R_{v m}(\mu \mathrm{m})$ & Average maximum profile valley depth \\
$\Delta_{a}(\mathrm{~m} \mathrm{rad})$ & Average slope of the profile \\
$\lambda_{a}(\mu \mathrm{m})$ & Average wavelength of the profile \\
$\Delta_{q}(\mathrm{~m} \mathrm{rad})$ & Root mean square (RMS) slope of the profile \\
$\lambda_{q}(\mu \mathrm{m})$ & Root mean square (RMS) wavelength of the profile \\
$H_{t p}(\mu \mathrm{m})$ & Profile section height difference \\
$R_{k}(\mu \mathrm{m})$ & Core roughness depth \\
$R_{p k}(\mu \mathrm{m})$ & Reduced peak height \\
$R_{v k}(\mu \mathrm{m})$ & Reduced valley depth \\
$M_{r 1}(\%)$ & Peak material component \\
$M_{r 2}(\%)$ & Valley material component \\
$S(\mu \mathrm{m})$ & Mean spacing of local peaks of the profile \\
$S_{m}(\mu \mathrm{m})$ & Surface material volume \\
$P_{c}(/ \mathrm{mm})$ & Peak count \\
$F D$ & Fractal dimension \\
&
\end{tabular}

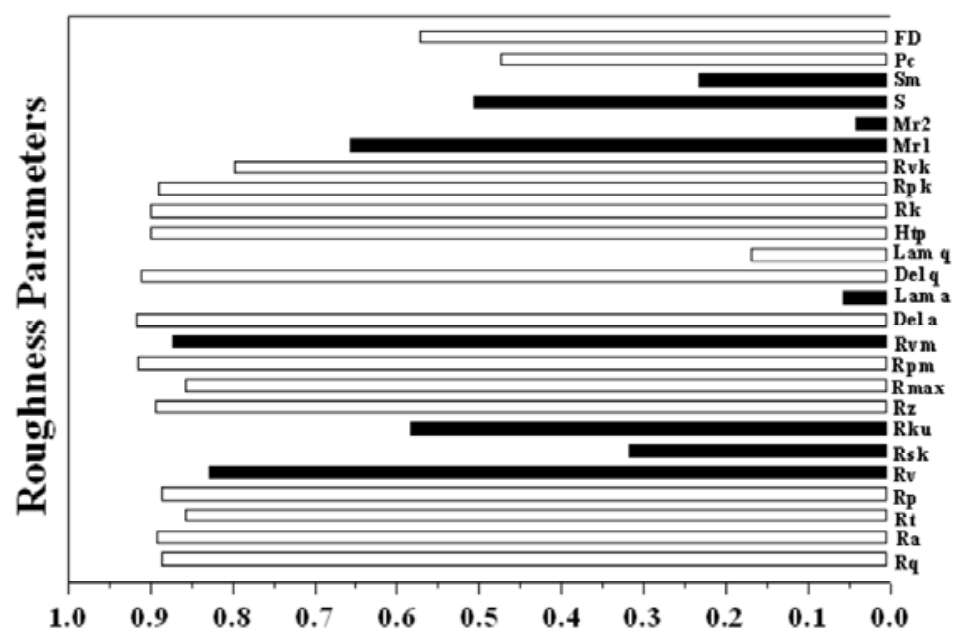

Correlation Coefficient

Figure 3. Correlation coefficient between coefficient of friction and roughness parameters under lubricated conditions. White and black bars represent positive and negative correlations, respectively. 
face roughness parameter. The maximum correlation coefficient (Pearson product moment correlation coefficient) between coefficient of friction and surface roughness parameters was calculated to be 0.92 under lubricated conditions for the case of pure $\mathrm{Cu}$. These values were obtained for the correlation coefficient between the coefficient of friction and the mean slope of the profile Del a (Gadelmawla et al 2002). Note that the roughness parameters, Del a is the arithmetic mean and Del $q$ is the root mean square value. Thus, the correlation coefficient between coefficient of friction and roughness parameters, namely Del a or Del $q$, indicates almost similar values. It can be seen from the figure 3 that there are other roughness parameters which correlate well with coefficient of friction (i.e. correlation coefficient $>0.8$ ). Similar observations can be made for other materials. Table 2 shows the correlation coefficient between coefficient of friction and roughness parameters for all materials that have correlation coefficient above 0.8 under lubricated conditions. It can be seen from this table that for a given material, many roughness parameters correlate well with coefficient of friction. For example, it can be observed that for the case of pure $\mathrm{Cu}$, among the 25 roughness parameters, 15 roughness parameters correlate well with coefficient of friction. However, for the case of $\mathrm{Al}$, only two roughness parameters correlate well with coefficient of friction and this number vary with material pair. However, an interesting aspect to note is that the surface roughness parameter, $\mathrm{Del} a$, correlates well with coefficient of friction for all materials investigated. It was shown earlier (Menezes et al 2006b) that the coefficient of friction values obtained under lubricated conditions were in the boundary lubrication regime representing the plowing component of friction. This clearly points to the fact that among the various roughness parameters the plowing component is controlled by the roughness parameter, Del $a$.

Table 2. Correlation coefficient between coefficient of friction and roughness parameters for different materials.

\begin{tabular}{|c|c|c|c|c|c|c|c|c|}
\hline $\begin{array}{l}\text { Roughness } \\
\text { parameter }\end{array}$ & $\begin{array}{c}\mathrm{Al}-4 \mathrm{Mg} \\
\text { alloy }\end{array}$ & Al- $8 \mathrm{Mg}$ & $\mathrm{Cu}$ & $\mathrm{Pb}$ & $\mathrm{Al}$ & $\mathrm{Mg}$ & $\mathrm{Zn}$ & $\mathrm{Sn}$ \\
\hline$R_{a}$ & 0.79 & & $0 \cdot 89$ & & & 0.80 & 0.76 & \\
\hline$R_{p}$ & 0.76 & & 0.89 & & & & 0.74 & \\
\hline$R_{z}$ & $0 \cdot 80$ & & $0 \cdot 90$ & & & & $0 \cdot 77$ & $0 \cdot 80$ \\
\hline$R_{p m}$ & $0 \cdot 83$ & & 0.91 & 0.79 & & & 0.78 & $0 \cdot 82$ \\
\hline$\Delta_{a}^{p m}$ & 0.90 & $0 \cdot 82$ & 0.92 & 0.85 & 0.87 & 0.89 & 0.88 & 0.90 \\
\hline$\Delta_{q}$ & $0 \cdot 88$ & & 0.91 & 0.83 & 0.84 & 0.86 & 0.86 & 0.88 \\
\hline$H_{t p}^{t}$ & $0 \cdot 83$ & & 0.90 & & & 0.83 & & \\
\hline$R_{k}$ & 0.83 & & 0.90 & & & 0.83 & 0.79 & $0 \cdot 82$ \\
\hline$R_{p k}$ & 0.69 & & 0.89 & & & & & \\
\hline$R_{v k}$ & & & $0 \cdot 80$ & & & & & \\
\hline$S$ & $-0 \cdot 85$ & & & & & & & \\
\hline$R_{k u}$ & & -0.72 & -0.58 & & & & & \\
\hline$S_{m}$ & & $-0 \cdot 80$ & & & & & & \\
\hline$F D$ & & 0.81 & & & & & & \\
\hline$R_{t}$ & & & 0.86 & & & & & \\
\hline$R_{v}$ & & & -0.83 & & & & & \\
\hline$R_{\max }$ & & & $0 \cdot 86$ & & & & & \\
\hline$R_{v m}$ & & & -0.87 & & & & -0.75 & \\
\hline$p_{c}$ & & & & 0.76 & & & 0.81 & \\
\hline$R_{q}$ & & & 0.89 & & & & 0.73 & \\
\hline
\end{tabular}




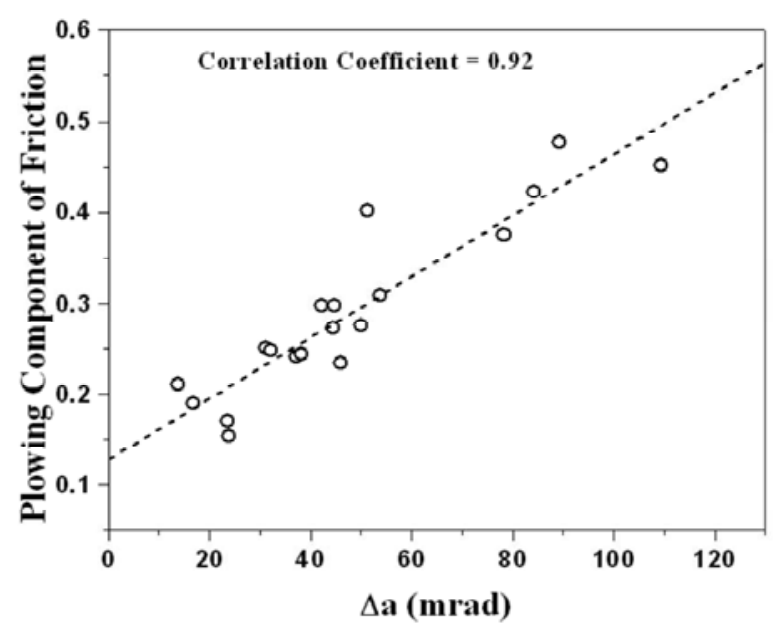

Figure 4. Correlation coefficient between coefficient of friction with surface roughness parameter, Del $a$.

The mean slope of the profile, Del $a$, is defined as the mean absolute profile slope over the assessment length. This parameter can be calculated by calculating all slopes between each two successive points of the profile, then calculating the average of such slopes. The mathematical expression for calculating the mean slope parameter is as follows (Gadelmawla et al 2002).

$$
\begin{aligned}
& \Delta_{a}=\frac{1}{L} \int_{0}^{L}\left|\frac{d y}{d x}\right| \cdot d x \text { or } \\
& \Delta_{a}=\frac{1}{n-1} \sum_{i=1}^{n-1} \frac{\delta y_{i}}{\delta x_{i}} .
\end{aligned}
$$

\section{Discussion}

Figure 4 shows the variation of coefficient of friction with roughness parameter, $\Delta_{a}($ Del $a)$, for various surface textures under lubricated conditions for pure $\mathrm{Cu}$. Higher values of $\mathrm{Del} a$ give higher coefficient of friction. For e.g. Type I surface texture has higher Del a value and also higher coefficient of friction. Type IV surface texture, on the other hand, has lower Del a values and friction. From this it can be inferred that the coefficient of friction depends on Del $a$ values irrespective of surface textures. The foregoing analysis points to the fact that the average values of coefficient of friction depends primarily on surface roughness parameter, Del $a$ for all the materials (namely, Al-4Mg alloy, $\mathrm{Al}-8 \mathrm{Mg}$ alloy, $\mathrm{Cu}, \mathrm{Pb}, \mathrm{Al}, \mathrm{Mg}, \mathrm{Zn}$ and $\mathrm{Sn}$ ) investigated. One of the early attempts to explain coefficient of friction was to relate it to the surface roughness, because surface is not generally smooth, instead consists of asperities. In addition, the roughness theory assumed that the frictional force is equal to the force required to climb up the asperity of slope $\theta$ and the coefficient of friction was given by $\mu=\tan \theta$ (Suh 1986). Koura \& Omar (1981) studied the effect of surface roughness parameters on friction and pointed out that the average slope of the asperities was found to be the single parameter that correlated best with coefficient of friction. Torrance (1995) also reported that the slope of the 
asperities can be used to predict boundary friction and concluded that friction coefficient falls as the asperity slope of the harder surface falls. In addition, Bhushan \& Nosonovsky (2004) reported that the coefficient of friction depends on the average slope of the rough surface. Further, Black et al (1988) conducted experiments using a wide range of wedge angles where the conditions of the tests were approximately plane strain. Black et al (1988) reported that the coefficient of friction increases as the wedge angle increases. Using slip line field theory, Challen \& Oxley (1979) and Petryk (1987) have also shown that the overall friction coefficient increases when the asperity (wedge) angle or the interfacial friction increases. Thus, from the above analysis, it can be inferred that the coefficient of friction primarily depends on mean slope of the profile. This means that when the slope of the harder asperities increases, the stresses required to overcome these asperities also increase during sliding. This situation induces a higher level of shear stresses in the pin and thus higher coefficient of friction. As higher values of Del a were found in the Type I surface texture, the coefficient of friction would be large. As the value of Del $a$ decreases, the stresses required to overcome the asperities is also expected to come down. Thus, for the Type IV surface texture, the lower values of Del $a$ causes lower stresses and corresponding coefficient of friction. Thus, the coefficient of friction would be higher for high Del a surface texture and lower for low Del a surface texture.

It can be seen that although the results can be explained in terms of slope of the asperities, still it does not explain surface characteristics completely. This situation is also discussed in terms of plane stress and plane strain (Menezes et al 2006c,e). It was observed in the literature that coefficient of friction, roughness parameters are also systemdependent (i.e. the roughness parameters which are available in the literature may not be universal). Hence more work needs to be done by considering, both roughness parameters and plane strain/plane stress hypothesis to explain the role of surface characteristics on friction.

\section{Conclusions}

In the present study, efforts were made to correlate the coefficient of friction with roughness parameters for various materials, namely, $\mathrm{Al}-4 \mathrm{Mg}$ alloy, $\mathrm{Al}-8 \mathrm{Mg}$ alloy, pure $\mathrm{Cu}, \mathrm{Pb}, \mathrm{Al}, \mathrm{Mg}$, $\mathrm{Zn}$ and pure $\mathrm{Sn}$. The conclusions based on the experimental results are as follows:

- Among the surface roughness parameters, which influence the coefficient of friction, the average or the mean slope of the profile - Del a was found to explain the variations best under lubricated conditions.

- The average value of coefficient of friction is strongly dependent on the mean slope of the profile regardless of surface texture for all the material investigated.

- The higher value of friction is attributed to the higher value of Del $a$ and vice versa.

\section{References}

Bello D O, Walton S 1987 Surface topography and lubrication in sheet-metal forming. Tribol. Int. 20(2): 59-65

Bhushan B, Nosonovsky M 2004 Scale effects in dry and wet friction, wear, and interface temperature.Nanotechnol. 15: 749-761 
Black A J, Kopalinsky E M, Oxley P L B 1988 An investigation of the different regimes of deformation which can occur when a hard wedge slides over a soft surface: The influence of wedge angle, lubrication and prior plastic working of the surface. Wear 123(1): 97-114

Challen J M, Oxley P L B 1979 An explanation of the different regimes of friction and wear using asperity deformation models. Wear 53(2): 229-235

Feder J 1988 Fractals. (New York: Plenum Press)

Gadelmawla E S, Koura M M, Maksoud T M A, Elewa I M, Soliman H H 2002 Roughness parameters. J. Mater. Process. Technol. 123(1): 133-145

Hasegawa M, Liu J, Okuda K, Nunobiki M 1996 Calculation of fractal dimension of machined surface profiles. Wear 192(1-2): 40-45

Hirst W, Hollander A E 1974 Surface finish and damage in sliding. Proc. R. Soc. London, Ser A 337: 379-394

Hu Z M, Dean T A 2000 A study of surface topography, friction and lubricants in metal forming. Int. J. Machine Tools and Manuf. 40: 1637-1649

Koura M M 1980 The effect of surface texture on friction mechanisms. Wear 63(1): 1-12

Koura M M, Omar M A 1981 The effect of surface parameters on friction. Wear 73(2): 235-246

Lakshmipathy R, Sagar R 1992 Effect of die surface topography on die-work interfacial friction in open die forging. Int. J. Machine Tools and Manuf. 32(5): 685-693

Lundberg J 1995 Influence of surface roughness on normal-sliding lubrication. Tribol. Int. 28(5): 317-322

Määttä A, Vuoristo P, Mäntylä T 2001 Friction and adhesion of stainless steel strip against tool steels in unlubricated sliding with high contact load. Tribol. Int. 34: 779-786

Malayappan S, Narayanasamy R 2004 An experimental analysis of upset forging of aluminium cylindrical billets considering the dissimilar frictional conditions at flat die surfaces. Int. J. Adv. Manuf. Technol. 23: 636-643

Menezes P L, Kishore, Kailas S V 2006a Effect of directionality of unidirectional grinding marks on friction and transfer layer formation of $\mathrm{Mg}$ on steel using inclined scratch test. Mater. Sci. and Eng. A429(1-2): 149-160

Menezes P L, Kishore, Kailas S V 2006b Effect of roughness parameter and grinding angle on coefficient of friction when sliding of Al-Mg alloy over EN8 steel. Trans. of the ASME: J. Tribol. 128(4): 697-704

Menezes P L, Kishore, Kailas S V 2006c Influence of surface texture on coefficient of friction and transfer layer formation during sliding of pure magnesium pin on 080 M40 (EN8) steel plate. Wear 261(5-6): 578-591

Menezes P L, Kishore, Kailas S V 2006d Studies on friction and transfer layer: Role of surface texture. Tribol. Lett. 24(3): 265-273

Menezes P L, Kishore, Kailas S V 2006e Studies on friction and transfer layer using inclined scratch. Tribol. Int. 39: 175-183

Myers N O 1962 Characterization of surface roughness. Wear 5(3): 182-189

Petryk H 1987 Slip line field solutions for sliding contact. Proc. Inst. Mech. Eng., Int. Conf., Tribol. Friction, Lubrication and Wear 50 years on, II: 987-994

Singh R, Melkote S N, Hashimoto F 2005 Frictional response of precision finished surfaces in pure sliding. Wear 258: 1500-1509

Staph H E, Ku P M, Carper H J 1973 Effect of surface roughness and surface texture on scuffing. Mechanism and machine theory 8: 197-208

Suh N P 1986 Tribophysics. (New Jersey: Prentice-hall, Inc., Englewood Cliffs)

Torrance A A 1995 Using profilometry for the quantitative assessment of tribological function: PCbased software for friction and wear prediction. Wear 181-183: 397-404

Wieleba W 2002 The statistical correlation of the coefficient of friction and wear rate of PTFE composites with steel counterface roughness and hardness. Wear 252(9-10): 719-729 